\title{
Identification of swine influenza A virus and Stenotrophomonas maltophilia co-infection in Chinese pigs
}

Dongjun Hou ${ }^{1 \dagger}$, Yuhai Bi ${ }^{1,2+}$, Honglei Sun ${ }^{1}$, Jun Yang ${ }^{1}$, Guanghua Fu', Yipeng Sun ${ }^{1}$, Jinhua Liư ${ }^{1,3}$ and Juan $\mathrm{Pu}^{1,4^{*}}$

\begin{abstract}
Background: Influenza virus virulence can be exacerbated by bacterial co-infections. Swine influenza virus (SIV) infection together with some bacteria is found to enhance pathogenicity.

Methods: SIV-positive samples suspected of containing bacteria were used for bacterial isolation and identification. Antimicrobial susceptibility testing was performed by disc diffusion methods. To investigate the interaction of SIV and the bacteria in vitro, guinea pigs were used as mammalian hosts to determine the effect on viral susceptibility and transmissibility. Differences in viral titers between groups were compared using Student's $t$-test.

Results: During surveillance for SIV in China from 2006 to 2009, seven isolates (24.14\%) of 29 influenza A viruses were co-isolated with Stenotrophomonas maltophilia from nasal and tracheal swab samples of pigs. Antimicrobial susceptibility testing showed that the bacteria possessed a high level of resistance towards clinically used antibiotics. To investigate the interaction between these two microorganisms in influencing viral susceptibility and transmission in humans, guinea pigs were used as an infection model. Animals were inoculated with SIV or S. maltophilia alone or co-infected with SIV and S. maltophilia. The results showed that although no transmission among guinea pigs was observed, virus-bacteria co-infections resulted in higher virus titers in nasal washes and trachea and a longer virus shedding period.

Conclusions: This is the first report of influenza virus co-infection with S. maltophilia in the Chinese swine population. Increased replication of virus by co-infection with multidrug resistant bacteria might increase the infection rate of SIV in humans. The control of S. maltophilia in clinics will contribute to reducing the spread of SIV in pigs and humans.
\end{abstract}

Keywords: Swine influenza virus, S. maltophilia, Co-infections, Guinea pigs

\section{Background}

Influenza A virus infection is a clinically and economically important pathogen causing respiratory disease in pigs worldwide. Swine influenza virus (SIV) subtypes H1N1, H3N2 and H1N2 can also cause zoonotic disease with flulike symptoms in humans [1]. The recent emergence of the pandemic $\mathrm{H} 1 \mathrm{~N} 1$ virus was potentially of swine origin and

\footnotetext{
*Correspondence: pujuanzgz@126.com

${ }^{\dagger}$ Equal contributors

'Key Laboratory of Animal Epidemiology and Zoonosis, Ministry of Agriculture, College of Veterinary Medicine, China Agricultural University, Beijing 100193, People's Republic of China

${ }^{4}$ College of Veterinary Medicine, China Agricultural University, No.2

Yuanmingyuan West Road, Beijing 100193, China

Full list of author information is available at the end of the article
}

provides a reminder that infection of pigs with influenza A viruses pose important public health concerns [2].

Influenza virus infections are usually exacerbated by secondary bacterial infections, and are one of the major causes of severe influenza pneumonia in humans, possibly due to the synergistic effect of these microorganisms during respiratory tract invasion [3,4]. It was reported that co-infection of SIV and bacteria such as Streptococcus pneumoniae, Haemophilus influenzae or Staphylococcus aureus leads to higher morbidity and mortality in mammals [5-7].

From our swine influenza surveillance work from 2006 to 2009 , samples were inoculated into specific pathogen free (SPF) eggs for viral isolation [8]. It was found that

\section{Biomed Central}


inoculated embryonated eggs of some SIV-positive isolates died during the isolation procedure. Visual inspection of these eggs showed that the allantoic fluid was turbid. From previous experience, the majority of SIVs do not cause egg death, as any bacteria in the swab are killed by the multiple antibiotics in the transport medium. Thus, we hypothesized that the collected samples contained bacteria that was not killed by antibiotics in the transport medium, and that these multidrug resistant bacteria survived by escaping antibiotic treatment, and might contribute to an increased chance of co-infection with influenza virus due to the enhancement of viral susceptibility and interspecies transmission. In light of reports of SIV infections in humans, especially in individuals that have had direct contact with pigs [9], this study aimed to identify co-infecting bacteria and investigate their interactions with SIV in viral replication and transmission using a guinea pig infection model.

\section{Results}

\section{Bacterial isolation and identification}

SIV-positive samples still containing bacteria after treatment with antibiotics in viral transport medium were subjected to bacterial isolation and identification. All of the isolates produced typically similar small $(<1 \mathrm{~mm})$, circular, convex, colorless colonies. Analysis with the RiboPrinter Microbial Characterization System demonstrated that all these samples contained Stenotrophomonas maltophilia. The isolates displayed a typical API 20 NE profile (1-4-32-3-4-1) with a good identification score of $99.9 \%$ at the species level (Table 1). Furthermore, the similarity of $16 \mathrm{~S}$ rRNA sequences from tested samples and $S$. maltophilia [GenBank: HQ246220] was $299 \%$. Thus, these findings demonstrated that these isolates were $S$. maltophilia. Among the 29 isolates, seven (24.14\%) viruses were coinfected with $S$. maltophilia: swine/Guangdong/7/06 (H3N2), swine/Shandong/133/07 (H3N2), swine/Fujian/
43/07 (H3N2), swine/Guangdong/106/07 (H3N2), swine/ Guangdong/211/2006 (H3N2), swine/Guangdong/109/ 2006 (H1N1) and swine/Guangdong/33/2006 (H1N1). Further antimicrobial susceptibility testing using the disc diffusion method showed that the bacteria were multidrug resistant and possessed a high degree of resistance towards clinically used antibiotics such as streptomycin, sulfadimidine, gentamicin, trimethoprim, ampicillin, amoxicillin, novobiocin, nitrofurantoin, cefotaxime, ceftazidime.

\section{Susceptibility in guinea pigs}

Guinea pigs have recently been shown to be an alternative mammalian model for the study of human infection with influenza A virus, especially for the study of viral transmissibility [10]. Thus, we used guinea pigs to evaluate the susceptibility and transmissibility of SIV or SIV co-inoculated with S. maltophilia. Among the seven swine influenza isolates, A/Swine/Guangdong/7/06 $(\mathrm{H} 3 \mathrm{~N} 2)$ belonged to a recent human-like lineage and possessed the closest genomic homology with human virus $\mathrm{A} / \mathrm{Moscow} / 10 / 99$ [8]. This virus was therefore selected for the animal experiments.

During the 14-day experimental observation period, no weight loss was observed following infection with SIV or S. maltophilia either alone or as a co-infection. However, guinea pigs co-inoculated with the virus and bacteria showed depression, while no obvious disease signs were observed in the virus or bacteria-inoculated groups. S. maltophilia were recovered from the tracheas and lungs of the bacteria-inoculated groups but not from the DPBS control group, which suggested that S. maltophilia successfully infected the guinea pigs. Viruses were recovered from nasal washes and tracheas but not from lungs, with the highest viral titers occurring on day 2 post-inoculation (p.i.). The yields of infectious virus were higher in nasal washes than in tracheas. The viral replication kinetics in the nasal washes and tracheas are

Table 1 Biochemical profile of the isolate with API 20 NE system

\begin{tabular}{|c|c|c|c|}
\hline Reactions/Enzymes & Results & Reactions/Enzymes & Results \\
\hline Reduction of nitrates & $+^{*}$ & Assimilation (mannitol) & - \\
\hline Indole production (tryptophane) & - & Assimilation ( $\mathrm{N}$-acetyl-glucosamine) & + \\
\hline Fermentation (glucose) & - & Assimilation (maltose) & + \\
\hline Arginine dihydrolase & - & Assimilation (Potassium gluconate) & - \\
\hline Urease & - & Assimilation (capric acid) & - \\
\hline Hydrolysis ( $\beta$-glucosidase) (esculin) & + & Assimilation (adipic acid) & - \\
\hline Hydrolysis (protease) (gelatin) & + & Assimilation (malate) & + \\
\hline$\beta$-galactosidase & + & Assimilation (trisodium citrate) & + \\
\hline Assimilation (glucose) & - & Assimilation (phenylacetic acid) & - \\
\hline Assimilation (arabinose) & - & Cytochrome oxidase & - \\
\hline Assimilation (mannose) & + & & \\
\hline
\end{tabular}

*t: positive result; -: negative result. 
shown in Figure 1. The duration of virus replication was longer in the co-inoculated group and viruses could be detected on day 8 p.i. The virus titers in nasal washes in the co-inoculated group were significantly higher $(\mathrm{P}<0.05)$ than in the group with single virus inoculation at all detection times. All guinea pigs inoculated with SIV showed seroconversion when tested on day 14 p.i. (Table 2).

\section{Transmissibility in guinea pigs}

Virus was not detected in any of the contact animals and seroconversion tests were all negative for SIV, suggesting that transmissibility did not occur in this experiment (Table 2).

\section{Histopathology in guinea pigs}

To compare the histopathological changes in guinea pigs inoculated with SIV or S. maltophilia alone or by co-inoculation, the trachea and lungs were removed from infected animals on day 4 p.i., were fixed in $10 \%$ neutral buffered formalin and processed for routine histology. The representative histopathology is shown in Figure 2A-D. The histopathological changes in guinea pigs infected with virus and bacteria were more severe than in groups solely infected with virus or bacteria. Guinea pigs infected with both virus and bacteria showed severe pathological lesions in the trachea, characterized by severely damaged tunica mucosa tracheae. A number of mucous epithelial cell exfoliates, inflammatory cells, and erythrocytes were found in the trachea. Neutrophils were the predominant inflammatory cell when analyzed at high magnification (Figure 2D). The virus-infected groups showed mild pathological lesions in the trachea, which were characterized by dropout of mucous epithelium and few inflammatory cells adhering to the surface of the trachea (Figure 2C). There were no apparent histological changes observed in the trachea of the bacteria-infected and control groups (Figure 2A-B).

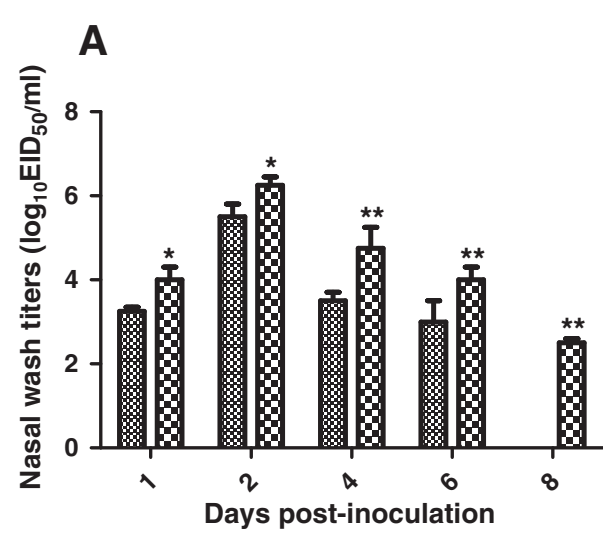

B

SIV-alone group

EI SIV-S.maltophilia group

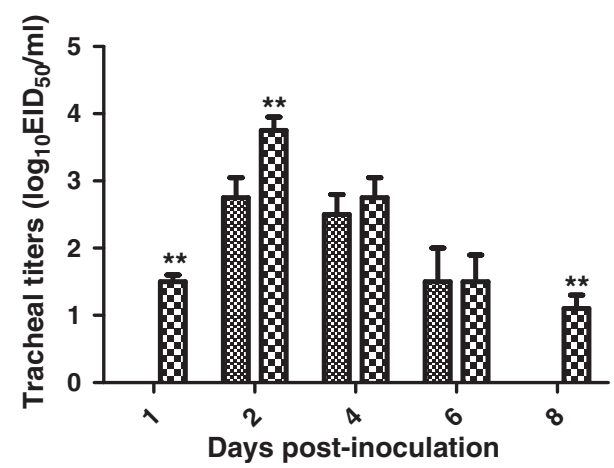

Figure 1 Replication of influenza virus A/Swine/Guangdong/7/06 (H3N2) in guinea pigs. Groups of 18 animals were inoculated intranasally with $100 \mu \mathrm{L}\left(10^{6} \mathrm{EID}_{50}\right)$ of virus, or a $100 \mu \mathrm{L}$ mixture of virus $\left(10^{6} \mathrm{EID}_{50}\right)$ and S. maltophilia $\left(1.5 \times 10^{7} \mathrm{CFU}\right)$. On days 1, 2, 4, 6 and 8 postinoculation, three animals from each group were euthanized. Nasal wash, tracheas and lungs were collected for virus titration in eggs. (A) Virus titers in nasal washes. (B) Virus titers in tracheas. Each bar represents the virus titer expressed as mean $\log _{10} \mathrm{EID}_{50} / \mathrm{mL} \pm \mathrm{SD}$. The lower limit of detection was $10^{1.5} \mathrm{EID}_{50} / \mathrm{mL}$, or $10^{1.5} \mathrm{EID}_{50} / \mathrm{mL}$ of tissue homogenate. Virus titers at each time point were compared between single virusinoculated and virus-bacterial co-inoculated groups. ${ }^{*}$ indicates statistically significant difference of means with $p<0.05$, ** indicates statistically significant differences of means with $p<0.01$. 
Table 2 Virus, clinical signs, virus replication, transmission and seroconversion of guinea pigs

\begin{tabular}{|c|c|c|c|c|c|c|}
\hline \multirow[t]{2}{*}{ Inoculum } & \multicolumn{3}{|c|}{ Inoculated guinea pigs } & \multicolumn{2}{|c|}{ Contact guinea pigs } & \multirow[t]{2}{*}{ Transmission } \\
\hline & Clinical signs & $\begin{array}{l}\text { Peak mean nasal } \\
\text { wash titer } \pm S D(\text { day) }\end{array}$ & $\begin{array}{l}\text { Seroconversion } \\
\text { (HI titer range) }\end{array}$ & $\begin{array}{l}\text { Virus detected } \\
\text { in nasal wash }\end{array}$ & $\begin{array}{l}\text { Seroconversion } \\
\text { (HI titer range) }\end{array}$ & \\
\hline Swine influenza virus (SIV) & None & $5.50 \pm 0.6(2)$ & $3 / 3^{*}(40)$ & $0 / 3$ & $0 / 3$ & None \\
\hline SIV + S. maltophilia & Depression & $6.25 \pm 0.4(2)$ & $3 / 3(40-80)$ & $0 / 3$ & $0 / 3$ & None \\
\hline
\end{tabular}

${ }^{*}$ Number of positive guinea pigs/total number; ${ }^{* *}$ Peak nasal wash titers are expressed as the mean $\log _{10} \mathrm{EID}_{50} / \mathrm{mL}^{\mathrm{S}} \mathrm{SD}{ }^{* * *}$ Serum was collected on day 14 p.i. for the virus inoculated group and on day 21 p.i. for the contact group, and homologous strains were used to detect SIV seroconversion with chicken red blood cells in hemagglutination inhibition assays. ${ }^{* * * *}$ The lower limit of detection was $10^{1.5} \mathrm{EID}_{50} / \mathrm{mL}$.

In addition, no apparent histological changes were observed in the lungs of all the infected and control groups.

\section{Discussion}

During the surveillance period (2006-2009), we found the first evidence for co-infection of SIV and S. maltophilia in pigs in several provinces in China, where the isolated S. maltophilia showed multidrug resistance. The coinfection of SIV and S. maltophilia has only previously been reported in Brazil [11].

S. maltophilia is an aerobic, non-fermentative, Gramnegative bacterium belonging to the genus Stenotrophomonas [12]. S. maltophilia is ubiquitous in aqueous environments, soil and plants, and frequently colonizes breathing tubes such as endotracheal or tracheostomy tubes, the respiratory tract and indwelling urinary catheters. It is a causal agent of infection and has gained considerable prominence in recent years as an important nosocomial pathogen associated with significant case/ fatality ratios in debilitated or immunosuppressed patients [13-17].

In 2004, S. maltophilia was first reported in pigs from China [18], which was followed by several reports describing bacteria infecting both healthy and diseased pigs [19-21]. However, the colonization rate of swine with S. maltophilia in China was unknown, and co-infection of S. maltophilia and influenza A virus had not been previously reported in the Chinese swine population.

In this study, the synergistic effect of SIV and S. maltophilia caused depression in co-infected guinea pigs.

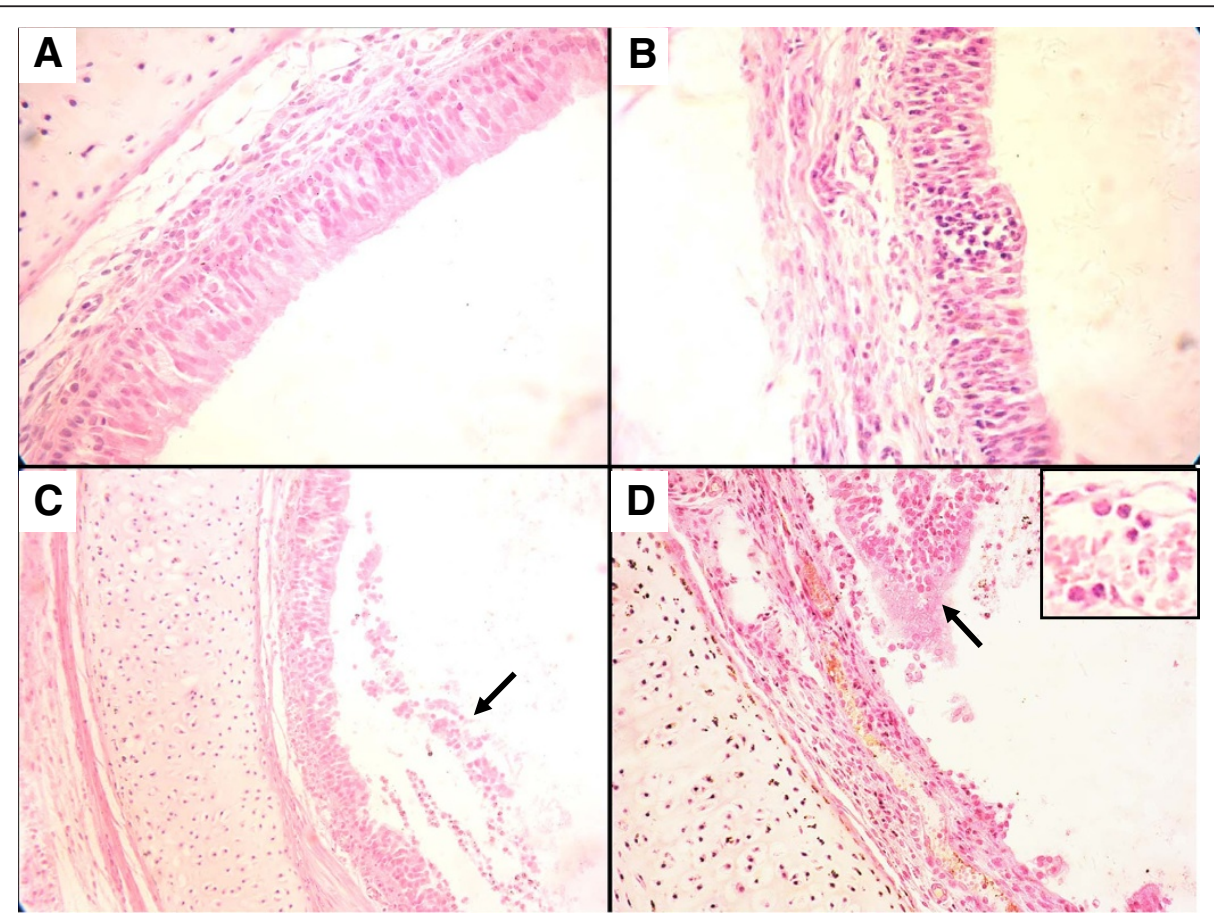

Figure 2 Representative histopathological changes in HE-stained trachea from inoculated guinea pigs day 4 post-inoculation.

(A) Negative control. No apparent histopathologic lesions. (B) Bacteria-infected group. No apparent histopathologic lesions. (C) Virus-infected group. Dropout of mucous epithelium and inflammatory cell infiltration (solid arrow). (D) Co-infected group. Dropout of mucous epithelium cells, with many neutrophils and erythrocytes present (solid arrow). Tissue sections were observed under a microscope (Nikon, Japan). Magnification: $(A, B$, and $D) \times 400 ; C \times 200$ 
Higher virus titers in nasal washes and tracheal samples and a longer period of virus shedding in nasal washes of co-infected animals was found in comparison with animals infected only with either virus or bacteria. In addition, the co-infected group showed more severe pathological lesions in the trachea than the other groups. This in vivo finding suggests that coinfection can enhance SIV replication during infection of guinea pigs. However, replication of the virus was still confined to the upper respiratory tract and was not found in the lungs, as is the case for most human influenza viruses [22-24]. Swine influenza viruses can cause disease in humans [1]. Several cases of coinfection of influenza A virus and S. maltophilia in humans have also been reported $[11,25]$. S. maltophilia is a multidrug resistant bacterium and possesses a high degree of resistance towards most commonly used broad-spectrum antibiotics, which is also confirmed in this study [26,27]. S. maltophilia can survive antibiotic treatment and co-infect hosts together with SIV, which can enhance viral replication and may increase the incidence of human infection with SIV, or SIV and S. maltophilia. During the treatment of SIV co-infection, controlling $S$. maltophilia will contribute to a reduction in illness and viral spread in pigs and human.

\section{Conclusions}

Here, we present data providing the first evidence for co-infection of influenza A virus and S. maltophilia in Chinese pigs. We show that co-infection contributed to the virulence of SIV in experimental guinea pigs. SIV and S. maltophilia pose an important public health concern, we believe it is of interest to further investigate coinfections involving these two infectious agents.

\section{Material and methods Samples}

From 2006 to 2009, 3,546 nasal and tracheal swab samples were collected for influenza surveillance in four main swine industrial provinces in China (Beijing, Fujian, Guangdong and Shandong). Twenty-nine strains of swine influenza A virus, including $19 \mathrm{H} 1 \mathrm{~N} 1$, a single H1N2 and 9 H3N2 strains were obtained. Genetic characterization of these viruses was reported in a previous study [8]. Swab sample transport medium contained minimum essential medium (MEM), $2 \times 10^{7} \mathrm{IU} / \mathrm{L}$ penicillin $\mathrm{G}, 1 \times 10^{7} \mathrm{IU} / \mathrm{L}$ streptomycin, $100 \mathrm{mg} / \mathrm{L}$ gentamicin, $100 \mathrm{mg} / \mathrm{L}$ nystatin, $100 \mathrm{mg} / \mathrm{L}$ polymyxin B and $1000 \mathrm{mg} / \mathrm{L}$ sulfanilamide. SIV-positive samples suspected of containing bacteria (assessed by egg death and turbidity of the allantoic fluid) were used for bacterial isolation and identification.

\section{Bacterial isolation and identification}

SIV-positive swab samples suspected of containing bacteria were streaked onto LB agar plates and incubated at $37^{\circ} \mathrm{C}$ for $24 \mathrm{~h}$. Bacterial colonies were collected and identified using a RiboPrinter Microbial Characterization System (DuPont Qualicon, DE, USA) [28]. Biochemical characterization was performed using an API $20 \mathrm{NE}$ (BioMerieux, France) and analyzed with Apiweb software (BioMerieux, France) according the manufacturer's instructions [29]. To confirm the identified result, several colonies selected randomly were used as template for $16 \mathrm{~S}$ rRNA sequencing as previously described [30]. Sequences were analyzed by Basic Local Alignment Search Tool (BLAST) for species identification as previously described [29].

\section{Antimicrobial susceptibility testing}

Antimicrobial susceptibility testing was performed by disc diffusion methods recommended by the Clinical and Laboratory Standards Institute (CLSI). The antimicrobial discs tested included ofloxacin, levofloxacin, streptomycin, sulfadimidine, gentamicin, azithromycin, trimethoprim, ciprofloxacin, minocycline, ampicillin, amoxicillin, novobiocin, vancomycin, nitrofurantoin, cefotaxime, ceftazidime. (supplied by Tiantan Company of Pharmaceutical and Biological Products Development, Beijing, China). Determination of the antimicrobial susceptibility test was performed according to the manufacturer's instructions, which followed the criteria of the CLSI. Reference strains Escherichia coli ATCC 25922 and Pseudomonas aeruginosa ATCC 27853 were used as quality control organisms in all antimicrobial susceptibility tests.

\section{Animals}

To investigate the interaction of SIV and S. maltophilia in influencing viral susceptibility and transmissibility in mammalian hosts, SPF/VAF (virus antibody free) Hartley strain female guinea pigs weighing 300-350 g and serologically negative for influenza virus were used. Animal experiments were approved by the Beijing Association for Science and Technology, the approve ID is SYXK (Beijing) 2007-0023, and complied with the guidelines of Beijing laboratory animal welfare and ethical of Beijing Administration Committee of Laboratory Animals. Zoletil 100 (tiletamine-zolazepam; Virbac S.A., Garros, France) was used to anesthetize animals by intramuscular injection $(10-15 \mathrm{mg} / \mathrm{kg})$.

\section{Susceptibility in guinea pigs}

Animals were inoculated with SIV or S. maltophilia alone or by co-infection of SIV and S. maltophilia. Groups of 18 animals were anesthetized and inoculated intranasally with $100 \mu \mathrm{L}\left(10^{6} 50 \%\right.$ egg infection dose, 
$E_{50}$ ) of virus, or $100 \mu \mathrm{L}$ of $1.5 \times 10^{7}$ colony forming units (CFU) S. maltophilia, or a $100 \mu \mathrm{L}$ mixture of the virus $\left(10^{6} \mathrm{EID}_{50}\right)$ and bacteria $\left(1.5 \times 10^{7} \mathrm{CFU}\right)$. Animals inoculated with Dulbecco's phosphate-buffered saline (DPBS) were used as controls. On days 1, 2, 4, 6 and 8 p.i., three animals from each group were euthanized. Nasal washes, tracheas and lungs were collected and a part of each organ was homogenized in DPBS-A (DPBS containing 2,000 U/mL penicillin $\mathrm{G}$ and $2.5 \mathrm{mg} / \mathrm{mL}$ streptomycin) and then $0.10 \mathrm{mg} / \mathrm{mL}$ vancomycin was added (the S. maltophilia isolate was sensitive to vancomycin) for virus titration by $\operatorname{EID}_{50}$ assay. Nasal washes were performed by instilling a total of $1 \mathrm{~mL}$ of DPBS-A into the nostrils and collecting liquid runoff into a sterile Petri dish. To confirm successful bacterial inoculation, tracheas and lungs were also collected for isolation and identification on day 4 p.i., as previously described [31]. Groups of the remaining three animals were observed for 2 weeks for body weight, signs of disease, and tested for SIV seroconversion on day 14 p.i.

\section{Transmissibility in guinea pigs}

For the contact transmission study, groups of 15 naive guinea pigs were housed with the virus-inoculated, or virus and bacteria co-inoculated animals at $24 \mathrm{~h}$ p.i. and observed for 21 days. On days 2, 4, 6 and 8 p.i., the nasal washes, tracheas and lungs of three contact animals for each group were collected and titrated for $\mathrm{EID}_{50}$ assay. Groups of the remaining three animals were observed over 21 days for body weight and signs of disease, and tested for seroconversion on day 21 post-contact.

\section{Histopathology}

On day 4 p.i., trachea and lung specimens from inoculated guinea pigs were fixed in $10 \%$ neutral buffered formalin, routinely processed, and embedded in paraffin. Sections (4- $\mu \mathrm{m}$ thickness) were stained with hematoxylin and eosin (HE).

\section{Statistical analysis}

Differences in viral titers between single virus-inoculated and virus-bacterial co-inoculated groups were compared using Student's $t$-test. A P-value less than 0.05 was considered statistically significant.

\section{Competing interests}

The authors declare that they have no competing interests.

\section{Authors' contributions}

$J P, D J H$ and YHB performed the research. JHL and JP developed the study plan and wrote the paper. JY collected samples and gathered clinical data. GHF and YPS analyzed the animal experimental data and edited the draft manuscript. HLS analyzed the histopathological data. All authors have read and approved the final manuscript.

\section{Acknowledgments}

The study was supported by the Specialized Research Fund for the Doctora Program of Higher Education (20090008120007), National Science Fund for Distinguished Young Scholars (31025029), the National Basic Research Program (973 Program, 2011CB504702), and the Program for Cheung Kong Scholars and Chinese Universities Scientific Fund (Project No.2011JS013).

\section{Author details}

${ }^{1}$ Key Laboratory of Animal Epidemiology and Zoonosis, Ministry of Agriculture, College of Veterinary Medicine, China Agricultural University, Beijing 100193, People's Republic of China. ${ }^{2}$ Chinese Academy of Sciences Key Laboratory of Pathogenic Microbiology and Immunology (CASPMI), Institute of Microbiology, Chinese Academy of Sciences, Beijing 100101, China. ${ }^{3}$ Shandong Animal Disease Control Center, Jinan 250022Shandong Province, P.R. China. ${ }^{4}$ College of Veterinary Medicine, China Agricultural University, No.2 Yuanmingyuan West Road, Beijing 100193, China.

Received: 3 November 2011 Accepted: 14 August 2012

Published: 22 August 2012

\section{References}

1. Peiris JS, Poon LL, Guan Y: Emergence of a novel swine-origin influenza A virus (S-OIV) H1N1 virus in humans. J Clin Virol 2009, 45:169-173.

2. Neumann G, Noda T, Kawaoka Y: Emergence and pandemic potential of swine-origin H1N1 influenza virus. Nature 2009, 459:931-939.

3. Callan RJ, Hartmann FA, West SE, Hinshaw VS: Cleavage of influenza A virus $\mathrm{H} 1$ hemagglutinin by swine respiratory bacterial proteases. J Virol 1997, 71:7579-7585.

4. Scheiblauer H, Reinacher M, Tashiro M, Rott R: Interactions between bacteria and influenza $A$ virus in the development of influenza pneumonia. J Infect Dis 1992, 166:783-791.

5. Cunha BA, Pherez FM, Durie N: Swine influenza (H1N1) and acute appendicitis. Heart Lung 2010, 39:544-546.

6. Barlow GD: Swine flu and antibiotics. J Antimicrob Chemother 2009, 64:889-894.

7. Cunha BA, Syed U, Mickail N: Fulminant fatal swine influenza (H1N1): Myocarditis, myocardial infarction, or severe influenza pneumonia? Heart Lung 2010, 39:453-458

8. Bi Y, Fu G, Chen J, Peng J, Sun Y, Wang J, Pu J, Zhang Y, Gao H, Ma G, et al: Novel swine influenza virus reassortants in pigs, China. Emerg Infect Dis 2010, 16:1162-1164

9. Nowotny N, Deutz A, Fuchs K, Schuller W, Hinterdorfer F, Auer H, Aspock H: Prevalence of swine influenza and other viral, bacterial, and parasitic zoonoses in veterinarians. J Infect Dis 1997, 176:1414-1415.

10. Lowen AC, Mubareka S, Tumpey TM, Garcia-Sastre A, Palese P: The guinea pig as a transmission model for human influenza viruses. Proc Natl Acad Sci U S A 2006, 103:9988-9992.

11. Mancini DA, Mendonca RM, Dias AL, Mendonca RZ, Pinto JR: Co-infection between influenza virus and flagellated bacteria. Rev Inst Med Trop Sao Paulo 2005, 47:275-280.

12. Palleroni NJ, Bradbury JF: Stenotrophomonas, a new bacterial genus for Xanthomonas maltophilia (Hugh 1980) Swings et al. 1983. Int J Syst Bacteriol 1993, 43:606-609.

13. Roilides E, Butler KM, Husson RN, Mueller BU, Lewis LL, Pizzo PA: Pseudomonas infections in children with human immunodeficiency virus infection. Pediatr Infect Dis J 1992, 11:547-553.

14. Denton M, Kerr KG: Microbiological and clinical aspects of infection associated with Stenotrophomonas maltophilia. Clin Microbiol Rev 1998, 11:57-80.

15. Penland RL, Wilhelmus KR: Stenotrophomonas maltophilia ocular infections. Arch Ophthalmol 1996, 114:433-436.

16. Vartivarian SE, Papadakis KA, Anaissie EJ: Stenotrophomonas (Xanthomonas) maltophilia urinary tract infection. A disease that is usually severe and complicated. Arch Intern Med 1996, 156:433-435.

17. Waters VJ, Gomez MI, Soong G, Amin S, Ernst RK, Prince A: Immunostimulatory properties of the emerging pathogen Stenotrophomonas maltophilia. Infect Immun 2007, 75:1698-1703.

18. Zhang H, Xie M, Zhang J, Tan Z, Cai J, Wanjun G: Cloning and sequencing of $16 \mathrm{~S}$ rRNA gene of Stenotrophomonas maltophilia from swine. Chinese Journal of Veterinary Science and Technology 2004, 34:3-5. 
19. Zhengqin $G$, Qiang Z, Zhengming $H$, Bingfei $Y$, Qiang $Y$ : Identification and susceptibility test of bacteria isolated from miniature pigs in China. Chinese Journal of Zoonoses 2010, 26:46-52.

20. Long C, Wenyi X, Lixing W, Mi L, Qigui Y, Manli H, Yingchun F: Isolation, identification and pathogenicity of stenotrophomonas maltophilia strain derived from swine high fever cases. Progress in Veterinary Medicine 2009, 30:25-28.

21. Xiangjie L, Sheng Y, Qiuquan W, Qingjun Z, Weiguo Z, Minxiang L, Sheng Z, Haojie Z: Study on the drug resistance and identification of Stenotrophomonas maltophilia isolated from swine. Fuoshan Science and Technology Institute Journal 2008, 26:41-43.

22. Smith AM, Ribeiro RM: Modeling the viral dynamics of influenza $A$ virus infection. Crit Rev Immunol 2010, 30:291-298.

23. Bender BS, Small PJ: Influenza: pathogenesis and host defense. Semin Respir Infect 1992, 7:38-45.

24. van Riel D, den Bakker MA, Leijten LM, Chutinimitkul S, Munster VJ, de Wit E, Rimmelzwaan GF, Fouchier RA, Osterhaus AD, Kuiken T: Seasonal and pandemic human influenza viruses attach better to human upper respiratory tract epithelium than avian influenza viruses. Am J Pathol 2010, 176:1614-1618.

25. Mancini DA, Alves RC, Mendonca RM, Bellei NJ, Carraro E, Machado AM, Pinto JR, Mancini FJ: Influenza virus and proteolytic bacteria co-infection in respiratory tract from individuals presenting respiratory manifestations. Rev Inst Med Trop Sao Paulo 2008, 50:41-46.

26. Lecso-Bornet M, Bergogne-Berezin E: Susceptibility of 100 strains of Stenotrophomonas maltophilia to three beta-lactams and five betalactam-beta-lactamase inhibitor combinations. J Antimicrob Chemother 1997, 40:717-720.

27. Sanders CC, Sanders WJ: beta-Lactam resistance in gram-negative bacteria: global trends and clinical impact. Clin Infect Dis 1992, 15:824-839.

28. Pangloli P, Dje Y, Ahmed O, Doane CA, Oliver SP, Draughon FA: Seasonal incidence and molecular characterization of salmonella from dairy cows, calves, and farm environment. Foodborne Pathog Dis 2008, 5:87-96.

29. Bosshard PP, Zbinden R, Abels S, Boddinghaus B, Altwegg M, Bottger EC: $16 S$ rRNA Gene Sequencing versus the API 20 NE System and the VITEK 2 ID-GNB Card for Identification of Nonfermenting Gram-Negative Bacteria in the Clinical Laboratory. J Clinical Microbiology 2006, 44(4):1359-1366.

30. Kajikazawa T, Sugita T, Nishikawa A: Comprehensive identification of bacteria in processed fresh edible sea urchin using $16 \mathrm{~S}$ ribosomal DNA sequence analysis: The products contain various food poisoning-related bacteria and opportunistic bacterial pathogens. J Health Science 2007, 53 (6):756-759.

31. Tang HB, DiMango E, Bryan R, Gambello M, Iglewski BH, Goldberg JB, Prince A: Contribution of specific Pseudomonas aeruginosa virulence factors to pathogenesis of pneumonia in a neonatal mouse model of infection. Infect Immun 1996, 64:37-43.

doi:10.1186/1743-422X-9-169

Cite this article as: Hou et al: Identification of swine influenza $A$ virus and Stenotrophomonas maltophilia co-infection in Chinese pigs.

Virology Journal 2012 9:169.

\section{Submit your next manuscript to BioMed Central and take full advantage of:}

- Convenient online submission

- Thorough peer review

- No space constraints or color figure charges

- Immediate publication on acceptance

- Inclusion in PubMed, CAS, Scopus and Google Scholar

- Research which is freely available for redistribution 